\title{
Relationship between adenosine deaminase polymorphism (c.22G $>$ A) and oxidative stress in sickle cell anemia
}

\author{
Danilo Grünig Humberto da Silva ${ }^{\text {a,b,* }}$, Edis Belini-Junior ${ }^{\text {a }}$, Lidiane de Souza Torres a , Jessika Viviani Okumura ${ }^{\text {a }}$ \\ Willian Marcel Barberino ${ }^{a}$, Renan Garcia de Oliveira ${ }^{a}$, Vanessa Urbinatti Teixeira a , \\ Clarisse Lopes de Castro Lobo ${ }^{\mathrm{c}}$, Eduardo Alves de Almeida ${ }^{\mathrm{b}, \mathrm{d}}$, Claudia Regina Bonini-Domingos ${ }^{\mathrm{a}}$ \\ a UNESP - Sao Paulo State University, Department of Biology, Hemoglobin and Hematologic Genetic Diseases Laboratory, Sao Paulo, Brazil \\ ${ }^{\mathrm{b}}$ UNESP - Sao Paulo State University, Department of Chemistry and Environmental Sciences, Sao Paulo, Brazil \\ c Hematological State Institute "Arthur de Siqueira Cavalcanti" - HEMORIO, Rio de Janeiro, Brazil \\ d FURB - Fundação Universidade Regional de Blumenau, Department of Natural Sciences, Santa Catarina, Brazil
}

\section{A R T I C L E I N F O}

\section{Article history:}

Received 25 May 2016

Revised 2 September 2016

Accepted 6 September 2016

Available online 13 September 2016

\section{Keywords:}

Hemoglobin S

Adenosine

Fetal hemoglobin

Hydroxycarbamide

\begin{abstract}
A B S T R A C T
The aim of this study was to identify, in people with sickle cell anemia (SCA), adenosine deaminase (ADA; c. $22 \mathrm{G}>\mathrm{A}$; rs73598374) polymorphism, and correlating it with oxidative stress markers. We evaluated 95 unrelated and diagnosed Brazilian sickle cell anemia (SCA) patients. All patients received a prophylactic treatment with folic acid of $5 \mathrm{mg} /$ day, while 41 (43.2\%) of them were under hydroxycarbamide (HC) treatment (average dose: $22 \mathrm{mg} / \mathrm{kg} / \mathrm{day}$ ). ADA polymorphism was identified by PCR-RFLP. Biochemical parameters were measured using spectrophotometric [catalase, glutathione $S$-transferase, glutathione peroxidase, glutathione reductase activities] and chromatographic methods [fetal hemoglobin ( $\mathrm{HbF}$ ), glutathione (GSH) and malondialdehyde (MDA) levels]. Among the 95 SCA patients, we identified 80 (84.2\%) wild homozygous for ADA (22GG), 15 (15.8\%) heterozygous (22GA) and none mutant homozygous (22AA), leading to an allelic frequency of 0.92 for the ancestral allele $(22 \mathrm{G})$ and 0.08 for the mutant one (22A). Unexpectedly, we did not observe any influence of $A D A$ polymorphism on oxidative stress markers, as well as interaction effects with HC usage. However, we confirmed a well-described protective effect of HC treatment on decreasing MDA levels $(p=0.03)$. Thus, we concluded that ADA $(22 \mathrm{G}>A)$ polymorphism does not play significant role in the disruption of sickle erythrocyte redox metabolism. (c) 2016 Elsevier B.V. All rights reserved.
\end{abstract}

\section{Introduction}

Sickle cell anemia (SCA) is a devastating genetic hemolytic disorder associated with a high morbidity and mortality (Stuart and Nagel, 2004; Rees et al., 2010; Piel et al., 2013). The underlying abnormality is a single nucleotide substitution (c.20A > T; rs334) in the gene that encodes the $\beta$-globin chain (Steinberg and Sebastiani, 2012). The mutated globin chain will form the abnormal hemoglobin $\mathrm{S}(\mathrm{HbS})$, due to a substitution of valine for glutamic acid at position six of the protein (Bunn, 1997). This substitution creates a hydrophobic patch in the HbS tetramer that results in a propensity to polymerize in its deoxygenated state, forming long polymers that distort the shape of the red blood cells (RBCs) (Hebbel, 1991). However, HbS polymerization is reversible; fibers "melt" as oxygen is taken up by the HbS and the normal discoid shape returns (Stuart and Nagel, 2004). The higher energy expenditure due

\footnotetext{
* Corresponding author at: UNESP - Sao Paulo State University, Department of Biology, Hemoglobin and Hematologic Genetic Diseases Laboratory, Rua Cristovão Colombo, 2265, Jardim Nazareth, CEP: 15054-000, São José do Rio Preto, São Paulo, Brazil.

E-mail address: danilogrunig@hotmail.com (D.G.H. da Silva).
}

to the increased metabolic turnover upon polymerization and depolymerization results in higher reactive oxygen species (ROS) production in sickle erythrocytes (Banerjee and Kuypers, 2004; Akohoue et al., 2007).

Despite our precise knowledge of the molecular defect that is associated with HbS in RBCs (Ingram, 1957; Christoph et al., 2005; Madigan and Malik, 2006) and recent progress in understanding the molecular events that control polymerization of $\mathrm{HbS}$ and sickling of erythrocytes (Ferrone, 2004; de Montalembert, 2008), the specific factors and signaling pathways that are involved in this process are unclear. In this way, Zhang et al. (Zhang et al., 2011) demonstrated that adenosine can enhance 2,3-bisphosphoglycerate (2,3-BPG) production via $\mathrm{A}_{2 \mathrm{~B}}$ receptor activation, suggesting that elevated adenosine had an unrecognized role in normal RBCs to promote oxygen $\left(\mathrm{O}_{2}\right)$ release and prevent acute ischemic tissue injury. However, in sickle erythrocytes, the beneficial role of excessive adenosine-mediated 2,3-BPG induction becomes detrimental by promoting deoxygenation, $\mathrm{HbS}$ polymerization and subsequent sickling.

Adenosine displays a complex metabolism in which it is generated intracellularly and extracellularly by degradation of adenine nucleotides 
(Zhang and Xia, 2012). In both media, the enzyme adenosine deaminase, encoded by $A D A$ gene (20q13.11), catalyzes the hydrolytic deamination of adenosine or 2'-deoxyadenosine to inosine or $2^{\prime}$ deoxyinosine and ammonia, contributing to the regulation of adenosine levels (Hirschhorn et al., 1994; Fredholm et al., 2005). Furthermore, a common functional variant of the $A D A$ gene has been described as a guanine to adenine transition (c.22G > A; rs73598374) which leads to the substitution of asparagine for aspartic acid at the eightieth codon of the gene (Hirschhorn et al., 1994). It has been found that this functional polymorphism leads to a decrease in ADA activity in erythrocytes and lymphocytes (Battistuzzi et al., 1981).

Taken the above observations into consideration, we hypothesized that the co-inheritance of SCA and $A D A(22 \mathrm{G}>\mathrm{A})$ polymorphism would enhance adenosine levels due to $A D A(22 \mathrm{G}>\mathrm{A})$ mutation, and through adenosine-mediated 2,3-BPG induction mechanism, exacerbate ROS generation inside the sickle erythrocytes, culminating in the worsening of the SCA patient oxidative condition. Thus, the aim of this study was to identify, in people with SCA, ADA (c. 22G>A; rs73598374) polymorphism, and correlating it with oxidative stress and antioxidant capacity markers.

\section{Methods}

\subsection{Subjects}

We evaluated 95 unrelated Brazilian SCA patients ( 53 women and 42 men; mean age: 24.4 years old; range: $10-59$ years old). All subjects were regularly in clinical follow-up in the Blood Center of Rio de Janeiro (RJ, Brazil) and had access to the same medication protocol established and regulated by the Brazilian Ministry of Health for the entire national territory. All the patients studied received a prophylactic treatment with folic acid of $5 \mathrm{mg} /$ day since the SCA diagnosis, while 41 (43.2\%) of them were under hydroxycarbamide (HC) treatment (average dose: $22 \mathrm{mg} /$ $\mathrm{kg} /$ day). The Data Safety Monitoring Board (DSMB) according to Brazilian Regulations approved the study.

After they gave their informed consent, all patients have answered a questionnaire in order to screen them according to the exclusion criteria listed as follows. Patients were asked specifically whether they were taking any nutritional supplements, nonsteroidal anti-inflammatory drugs (NSAID), opioids, or iron chelating agents, e.g. Further exclusion criteria were pregnant women, smokers or drinkers and patients who had had a stroke, pain and/or hemolytic crisis, or received blood transfusion within the 120 days prior to the study start. The medications used were accessed and those ones taking medication known to affect the analyzed parameters (such as acetylsalicylic acid, antibiotics or vitamins) within $24 \mathrm{~h}$ of sample collection were excluded. We confirmed the information given in questionnaires by reviewing each patient's medical records from the Blood Center database under supervision of clinicians responsible for the patients.

\subsection{Biological samples}

Blood samples (about $8 \mathrm{~mL}$ ) were collected through venipuncture in ethylenediamine tetra acetic acid (EDTA) tubes. Four milliliters $(\mathrm{mL})$ of whole blood were used for cytological, electrophoretic and chromatographic hemoglobin identification tests, as well as for DNA extraction from leukocytes for further molecular analysis. The other $4 \mathrm{~mL}$ were firstly used to prepare hemolysate for catalase activity analysis whole blood diluted in ultrapure water $(1: 50, v / \mathrm{v})$. Then the blood samples were centrifuged in a refrigerated centrifuge at $800 \mathrm{~g}$ for $15 \mathrm{~min}$ at $4{ }^{\circ} \mathrm{C}$ in order to obtain plasma for lipid peroxidation assay while buffy coat were carefully removed. The erythrocytes obtained were washed three times with cold phosphate-buffered saline (PBS - $136 \mathrm{mM} \mathrm{NaCl}$, $3 \mathrm{mM} \mathrm{KCl}, 10 \mathrm{mM} \mathrm{Na}{ }_{2} \mathrm{HPO}_{4} / \mathrm{KH}_{2} \mathrm{PO}_{4}$, $\mathrm{pH}$ 7.4). The supernatant and buffy coat were carefully removed after each wash. Finally, the erythrocytes were diluted in a $3.5 \mu \mathrm{M}$ 2-mercaptoethanol $10 \mu \mathrm{M}$ NADP $2.7 \mathrm{mM}$
EDTA hemolyzing solution (1:20, v/v) for glutathione $S$-transferase, glutathione peroxidase and glutathione reductase activities and glutathione content measurement. All hemolysates and plasma samples were immediately frozen at $-80^{\circ} \mathrm{C}$ until the analysis.

\subsection{Hemoglobin identification tests}

Cell morphology microscopic analysis was performed on the stained blood using May-Grünwald-Giemsa at photonic microscopy using $40 \times$ objective (Bonini-Domingos, 2006). Hb phenotype identification was performed using electrophoresis on cellulose acetate $\mathrm{pH} 8.6$ (Marengo-Rowe, 1965), and agar electrophoresis at pH 6.2 (Vella, 1968). The $\mathrm{Hb}$ fraction quantification was obtained using high performance liquid chromatography (HPLC) by the automated VARIANT ${ }^{\mathrm{TM}}$ equipment (Bio-Rad Laboratories, Hercules, CA, USA), according to manufacturer's manual.

\subsection{Molecular analysis}

DNA was extracted from peripheral blood leucocytes and isolated by phenol-chloroform methodology, according to Sambrook et al. (Sambrook et al., 1989). HBB*S homozygous genotype was confirmed by molecular analysis by PCR-RFLP using DdeI as restriction endonuclease (New England BioLabs, Ipswich, MA, USA) (Saiki et al., 1985). ADA (c.22G $>$ A) polymorphism was assessed through PCR-RFLP using FastDigest TaqI (Thermo Fisher Scientific Inc., Waltham, MA, USA), according to Safranow et al. (Safranow et al., 2007).

\subsection{Biochemical measurements}

Lipid peroxidation levels were assessed in the plasma samples by the product formed from malondialdehyde (MDA) and thiobarbituric acid (TBA), according to Silva et al. (Silva et al., 2015). The product was detected by high performance liquid chromatography coupled to UV/Vis detector (UV/Vis-HPLC) (de Almeida et al., 2003; de Almeida et al., 2004). The HPLC system consisted of ESA584 pump and an ESA526 UV/Vis detector set in $532 \mathrm{~nm}$. The MDA-TBA derivative extracts were separated by a Shimadzu (Kyoto, Japan) C18 column $(150 \times 4.6 \mathrm{~mm}$, $5 \mu \mathrm{m}$ ) that was fitted with a guard column cartridge of the same composition. The mobile phase (potassium phosphate $0.05 \mathrm{M}, \mathrm{pH} 7.0$, with $40 \%$ methanol) was pumped at an isocratic flow of $1 \mathrm{~mL} \mathrm{~min}^{-1}$. Chromatogram monitoring and peak identification and quantification were performed using the EZ Chrom Elite software (Agilent Technologies, Santa Clara, CA, USA). The calculations were based on a calibration curve previously constructed and prepared according to same procedure used for the samples from authentic standards. The results were expressed in $\mathrm{ng} / \mathrm{mL}$.

Catalase (CAT) (Beutler, 1975), glutathione S-transferase (GST) (Keen et al., 1976), glutathione peroxidase (GPx) (Sies et al., 1979), and glutathione reductase (GR) (Beutler, 1969), activities were determined spectrophotometrically, while GSH concentration was determined HPLC coupled to a coulometric electrochemical detection (ECDHPLC) (Rodriguez-Ariza et al., 1994). A hemolysate aliquot was filtered through Millex syringe filter units $(0.22 \mu \mathrm{m})$ and directly injected into the HPLC system, consisted of ESA584 pump and an electrochemical coulometric detector (ESA Coulochem III, Bedford, MA, USA) with potential set at $650 \mathrm{mV}$. The column was an ESA C18 $(250 \times 4.6 \mathrm{~mm}$, $5 \mu \mathrm{m}$ ) also fitted with a guard column cartridge of the same composition. The mobile phase consisted of sodium phosphate $0.05 \mathrm{M}$, octanesulfonic acid $0.025 \mathrm{M}, \mathrm{pH} 2.5$, with acetonitrile $(2 \% ; \mathrm{v} / \mathrm{v})$ was pumped at an isocratic flow of $0.9 \mathrm{~mL} / \mathrm{min}$.

Chromatogram monitoring and peak identification and quantification were performed using the same software used in the lipid peroxidation assay. The calculations were based on a calibration curve previously constructed by injecting authentic GSH standards into the 
HPLC system. The antioxidant enzymes were expressed in $\mathrm{U} / \mathrm{mL}$, while GSH levels were in $\mu \mathrm{M}$.

\subsection{Statistical analysis}

Statistical analysis were performed in groups with at least three individuals using the Statistica 8.0 software (StatSoft Inc., Tulsa, OK, USA), while the graphics were done using GraphPad Prisma version 5.01 for Windows (GraphPad Software, La Jolla, CA, USA).

We assessed data normality by using Normal Probability Plots of Residuals. Thus, some data were either transformed into $\log _{10}$ or identified as outliers and removed from comparison analysis. We also tested data homoscedasticity by Levene's test, assuming a significance level of 0.05 . For comparison analysis, we used General Linear Models (GLMs), because these approaches generalize to unbalanced designs and designs with more factors, including crossed and nested, and combinations of categorical and continuous variables (Quinn and Keough, 2002; McDonald, 2014). That way we have established the ADA genotypic distribution and HC usage as predictors, age and gender as covariates, and the biochemical parameters evaluated as dependent variables. If appropriate, we applied the Tukey-Kramer post hoc test, a simple and reliable multiple comparison for unequal sample size (Quinn and Keough, 2002).

Wilk's $\lambda$ test was performed as a multivariate counterpart of a univariate $R^{2}$, that is, it indicates the proportion of generalized variance in the dependent variables that is accounted for by the predictors. In order to assess association degree between biochemical parameters and $\mathrm{HbF}$ levels, we used Pearson's correlation. Data were expressed as mean $\pm 95 \%$ confidence intervals of their biological values and we considered $p<0.05$ as statistically significant (Quinn and Keough, 2002; McDonald, 2014).

\section{Results}

Among the 95 SCA patients evaluated, we identified 80 (84.2\%) wild homozygous for $A D A$ (22GG), 15 (15.8\%) heterozygous (22GA) and none mutant homozygous (22AA), leading to an allelic frequency of 0.92 for the ancestral allele (22G) and 0.08 for the mutant one (22A). Due to the lack of mutant homozygous, and as $\mathrm{HC}$ is an important modulator of SCA oxidative status, we have compared the effects of ADA 22A polymorphism between wild homozygous (GG) and heterozygous (GA), the influence of $\mathrm{HC}$ using between patients treated $\left.\left(\mathrm{HC}^{+}\right)\right]$or not treated with $\mathrm{HC}\left(\mathrm{HC}^{-}\right)$, as well as their interaction $\left(A D A 22 \mathrm{~A}^{*} \mathrm{HC}\right.$ usage).

Unexpectedly, the presence of $A D A 22 \mathrm{~A}$ allele did not influence any of the oxidative stress parameters assessed, as well as we did not observe any interaction effects (Fig. 1). We only observed a well-documented HC effect on lipid peroxidation levels. Those patients treated with HC showed lower MDA levels [514.8 ng/mL (95\% CI: 452.1577.5)] than the patients untreated [378.8 ng/mL (95\% CI: $309.9-$ $447.7)$ ], regardless the presence of mutation $(p=0.03)$. Furthermore, Wilk's $\lambda$ statistic agreed with the univariate analysis, showing that a
A)

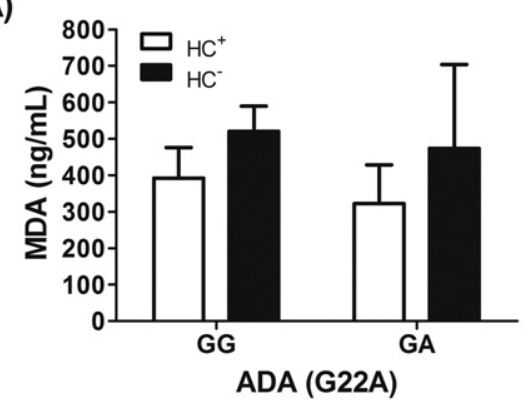

C)

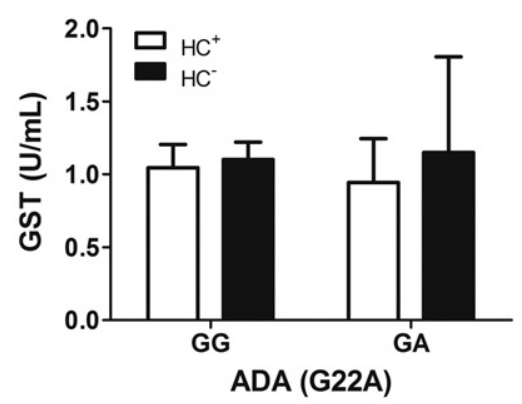

E)

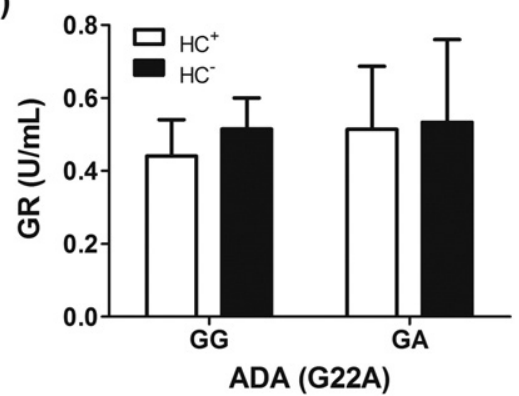

B)

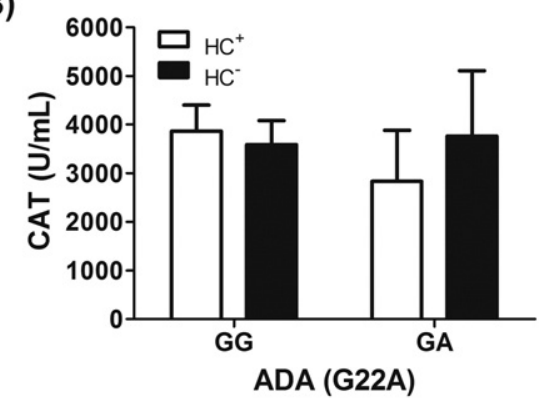

D)

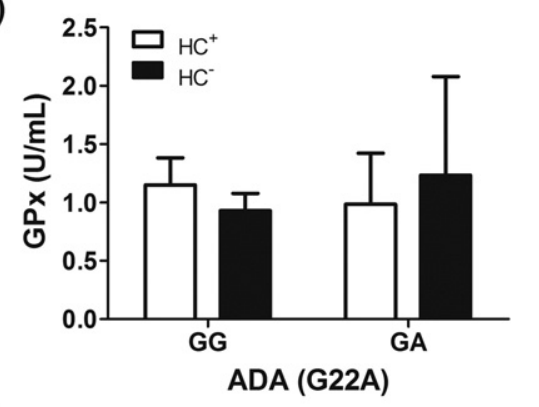

F)

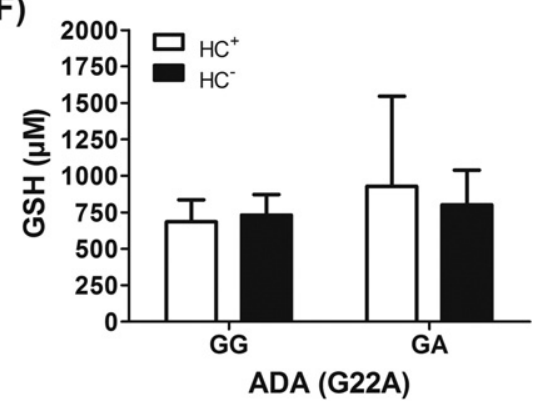

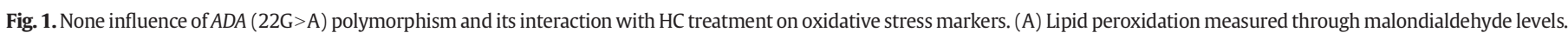

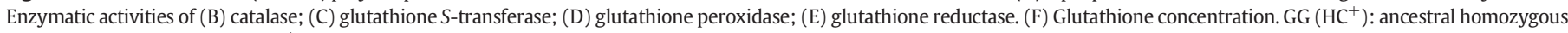

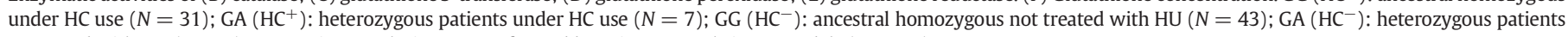
untreated with $\mathrm{HU}(N=6)$. Comparison analysis were performed by using General Linear Models $(P>0.05)$. 
Table 1

Effects of $A D A 22 \mathrm{~A}$ polymorphism, HC usage and their interaction on the biochemical parameters measured.

\begin{tabular}{lllll}
\hline Source & df & Wilk's $\lambda$ & $F$ & $P$ values \\
\hline ADA 22 A polymorphism & 7,46 & 0.90 & 0.72 & 0.64 \\
HC usage & 7,46 & 0.74 & 2.30 & 0.04 \\
ADA 22 A*HC usage & 7,46 & 0.87 & 0.97 & 0.46
\end{tabular}

$A D A$ : adenosine deaminase gene; HC: hydroxycarbamide; df: degree of freedom; $F$ : ratio of two mean square values.

significant proportion of the variance in the combination of response variables (MDA levels, activities of CAT, GST, GPx and GR, and GSH content) is accounted for HC usage effects (Table 1).

In order to better understand the non-participation of $A D A 22 \mathrm{~A}$ polymorphism in the expression of oxidative stress markers, further investigation was carried out according to $\mathrm{HbF}$ amount of SCA patients, because $\mathrm{HbF}$ is capable of changing the intracellular concentrations of $\mathrm{HbS}$ that dictate the pace and extent of polymerization(Damanhouri et al., 2015). Thus, we analyzed the association degree between HbF levels and biochemical markers studied in SCA patients heterozygous for $A D A$ polymorphism, since they showed high $\mathrm{HbF}$ levels variation (mean value: $8.6 \%$; range: $0.5-23 \%$ ). However, we found no correlation between $\mathrm{HbF}$ amount and each variable measured (Fig. 2).

A)

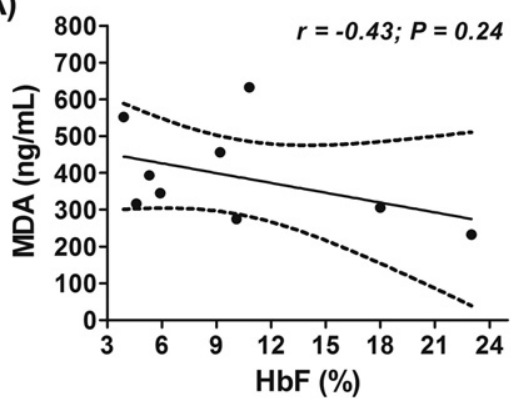

C)

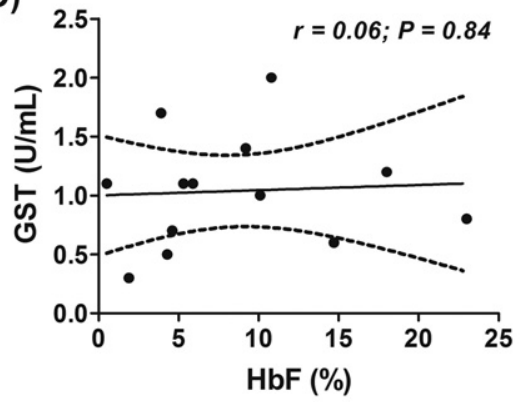

E)

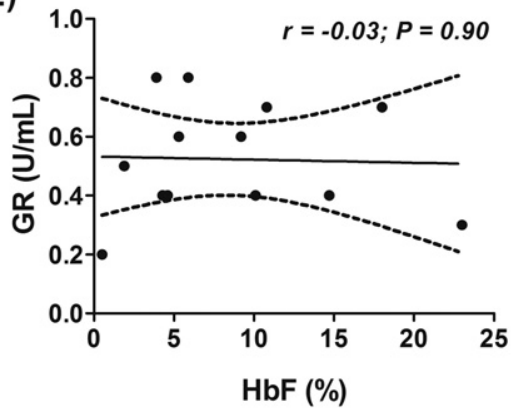

\section{Discussion}

Even with improved knowledge of the human genome, development of new genomic tools and identification of single nucleotide polymorphisms (SNPs) associated with subphenotypes of sickle cell disease (SCD) by genome-wide association studies (GWAS) (Fertrin and Costa, 2010), there is still a major challenge to combine all these variables and establish potential predictors of the SCD severity (Lettre, 2012). In addition, the understanding of SCA pathophysiology has gradually increased (Rees and Gibson, 2012), and among the new evidences, oxidative stress has been increasingly related to both cause and consequence of inflammation, hemolysis, vasculopathy, vaso-occlusion, infection, injury by ischemia/reperfusion, e.g. (Rees et al., 2010). However, studies associating genetic and biochemical markers are scarce, thus this study, to our knowledge, yields a unique opportunity in which both genetic factor (ADA polymorphism) and oxidative stress markers were simultaneously measured and correlated with $\mathrm{HbF}$ levels and $\mathrm{HC}$ use in persons with SCA.

The frequency of mutated allele in ADA gene (22A) is estimated at 0.06 in Western populations, lower among individuals of African descents and higher in Southeast Asian populations (Hopkinson et al., 1969; Weissmann et al., 1982; Hirschhorn et al., 1994). Previous studies from Brazilian population showed different allele frequencies. For instance, Dutra et al. (Dutra et al., 2010) obtained a 0.11 allele (22A) frequency for individuals from Rio Grande do Sul State. While, Nunes et

B)

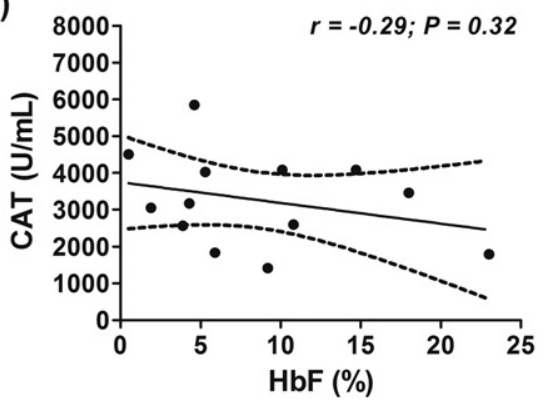

D)

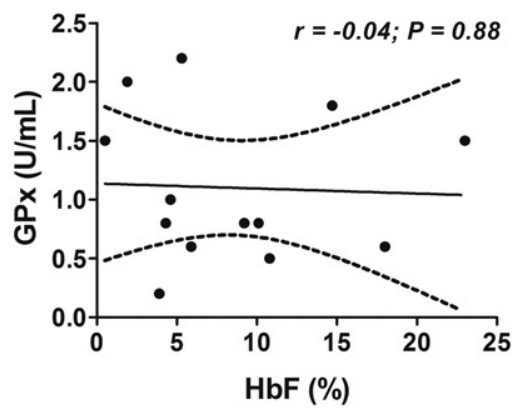

F)

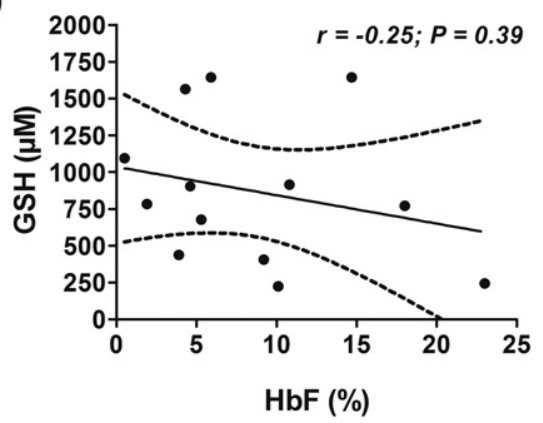

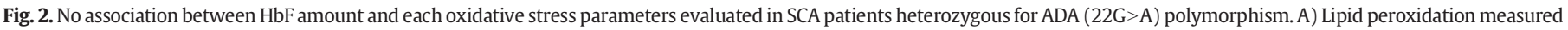

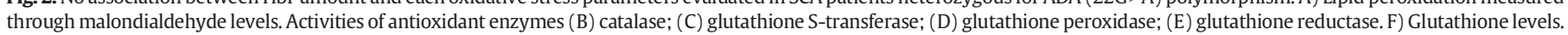
Dashed line indicates 95\% confidence band of best-fit line. All correlation analysis were made by Pearson's test. 
al. (Nunes et al., 2011) and Mazzotti et al. (Mazzotti et al., 2012) found a frequency about 0.05 for people from Sao Paulo State. These data are in accordance to studies developed in European populations (Persico et al., 2000; Safranow et al., 2007; Bachmann et al., 2012). This way, we found a frequency lower when compared to those reported for Caucasians and higher than that expected for African descents that might to be only the reflection of ethnic and racial admixture of our population. Moreover, to our knowledge, this is the first report about $A D A(22 \mathrm{G}>\mathrm{A})$ polymorphism in people with SCA from Rio de Janeiro State.

During periods of cellular hypoxia or stress, adenosine is released from cells along with the adenine nucleotides, ATP, ADP, and AMP, which are converted to adenosine by ectonucleotidases (Jacobson and Gao, 2006; Eltzschig and Carmeliet, 2011). This response is even more pronounced in SCA patients due to increased amounts of ATP in the circulation derived from chronic sickle red cell hemolysis and tissue damage from vasoocclusion (Hasko et al., 2008). This observation causes the postulated hypothesis of this study is more plausible, but we did not observe any influence of $A D A$ polymorphism on oxidative stress markers evaluated. Firstly, we thought that it could be the result of a known protective effect of $\mathrm{HbF}$ levels shown by Dasgupta et al. (Dasgupta et al., 2010) in SCA transgenic mice, and further confirmed in SCA patients by Silva et al. (Silva et al., 2011), in which Hb F protective effect is primarily mediated by decreased intravascular sickling, resulting in a decreased oxidative stress. However, we found no association between $\mathrm{HbF}$ levels and each biochemical parameters assessed. It is worth noting that the lack of mutant homozygotes and the small number of heterozygous might be affecting the results. Notwithstanding, even with a small sample size, our results have left perspectives for further studies to better address this hypothesis.

Although, the enzyme encoded by the A22 allele has about 35\% less catalytic activity than enzyme encoded by G22 allele, individuals carrying one copy of mutated allele display 15-20\% lower activity compared to ancestral homozygotes (Battistuzzi et al., 1981). This way, we demonstrated that enzyme inefficiency caused by mutation is not sufficient to trigger a worsening in oxidative outcome of people with SCA. Nevertheless, Safranow et al. (Safranow et al., 2007) demonstrated an association of $A D A 22 \mathrm{~A}$ allele with decreased risk of coronary artery disease. While Mi et al. (Mi et al., 2008) showed that mice lacking ADA developed priapic activity and penile vascular fibrosis. Recently, Cita et al. (Cita et al., 2016) did not observe any relation between the same SNP ( $A D A$; rs73598374) and a hemolytic index calculated through lactate dehydrogenase, aspartate aminotransferase, reticulocytes and total bilirubin in 150 SCA patients from Guadeloupe. Thus, further studies with larger sample size and association with clinical manifestations can predict the relative risk generated by co-inheritance of $A D A$ $(22 \mathrm{G}>\mathrm{A})$ polymorphism and SCA in disease progression.

In conclusion, we showed that $A D A(22 \mathrm{G}>\mathrm{A})$ polymorphism does not play significant role in the disruption of sickle erythrocyte redox metabolism. However, taking into consideration the studies summarized above, we suggest that this polymorphism might be involved in the broad spectrum of SCA phenotypic expression.

\section{Conflict of interest disclosure}

The authors declare no competing financial or relationship with other people or organizational interests. Furthermore, the authors have materially participated in the research and/or article preparation and approved the final article version.

\section{Acknowledgments}

This work has the financial support of the Brazilian foundations: "Conselho Nacional de Desenvolvimento Científico e Tecnológico CNPq" (140911/2011-1), "Fundação de Amparo à Pesquisa do Estado de São Paulo - FAPESP-CEPID-Redoxoma (2013/07937-8)” and
"Coordenação de Aperfeiçoamento de Pessoal de Nível Superior CAPES". E.A. Almeida is a fellowship of productivity of CNPq.

\section{References}

Akohoue, S.A., Shankar, S., Milne, G.L., Morrow, J., Chen, K.Y., Ajayi, W.U., Buchowski, M.S., 2007. Energy expenditure, inflammation, and oxidative stress in steady-state adolescents with sickle cell anemia. Pediatr. Res. 61, 233-238.

Bachmann, V., Klaus, F., Bodenmann, S., Schafer, N., Brugger, P., Huber, S., Berger, W., Landolt, H.P., 2012. Functional ADA polymorphism increases sleep depth and reduces vigilant attention in humans. Cereb. Cortex 22, 962-970.

Banerjee, T., Kuypers, F.A., 2004. Reactive oxygen species and phosphatidylserine externalization in murine sickle red cells. Br. J. Haematol. 124, 391-402.

Battistuzzi, G., Iudicone, P., Santolamazza, P., Petrucci, R., 1981. Activity of adenosine deaminase allelic forms in intact erythrocytes and in lymphocytes. Ann. Hum. Genet. 45, 15-19.

Beutler, E., 1969. Effect of flavin compounds on glutathione reductase activity: in vivo and in vitro studies. J. Clin. Invest. 48, 1957-1966.

Beutler, E., 1975. Red Cell Metabolism: A Manual of Biochemical Methods. Grune \& Stratton, New York.

Bonini-Domingos, C.R., 2006. Metodologias laboratoriais para o diagnóstico de hemoglobinopatias e talassemias. Inovação Distribuidora de Livros LTDA.

Bunn, H.F., 1997. Pathogenesis and treatment of sickle cell disease. N. Engl. J. Med. 337, 762-769.

Christoph, G.W., Hofrichter, J., Eaton, W.A., 2005. Understanding the shape of sickled red cells. Biophys. J. 88, 1371-1376.

Cita, K.C., Ferdinand, S., Connes, P., Brudey, L., Tressieres, B., Etienne-Julan, M., Lemonne, N., Tarer, V., Elion, J., Romana, M., 2016. Association of adenylyl cyclase 6 rs3730070 polymorphism and hemolytic level in patients with sickle cell anemia. Blood Cells Mol. Dis. 58, 21-25.

Damanhouri, G.A., Jarullah, J., Marouf, S., Hindawi, S.I., Mushtaq, G., Kamal, M.A., 2015. Clinical biomarkers in sickle cell disease. Saudi J. Biol. Sci. 22, 24-31.

Dasgupta, T., Fabry, M.E., Kaul, D.K., 2010. Antisickling property of fetal hemoglobin enhances nitric oxide bioavailability and ameliorates organ oxidative stress in transgenic-knockout sickle mice. Am. J. Phys. Regul. Integr. Comp. Phys. 298, R394-R402.

de Almeida, E.A., Marques Sde, A., Klitzke, C.F., Bainy, A.C., de Medeiros, M.H., Di Mascio, P., Loureiro, A.P., 2003. DNA damage in digestive gland and mantle tissue of the mussel Perna perna. Comp. Biochem. Physiol. C: Toxicol. Pharmacol. 135c, 295-303.

de Almeida, E.A., Miyamoto, S., Bainy, A.C., de Medeiros, M.H., Di Mascio, P., 2004. Protective effect of phospholipid hydroperoxide glutathione peroxidase (PHGPX) against lipid peroxidation in mussels Perna perna exposed to different metals. Mar. Pollut Bull. 49, 386-392.

de Montalembert, M., 2008. Management of sickle cell disease. BMJ 337, a1397.

Dutra, G.P., Ottoni, G.L., Lara, D.R., Bogo, M.R., 2010. Lower frequency of the low activity adenosine deaminase allelic variant (ADA1*2) in schizophrenic patients. Rev. Bras. Psiquiatr. 32, 275-278.

Eltzschig, H.K., Carmeliet, P., 2011. Hypoxia and inflammation. N. Engl. J. Med. 364, 656-665.

Ferrone, F.A., 2004. Polymerization and sickle cell disease: a molecular view. Microcirculation $11,115-128$.

Fertrin, K.Y., Costa, F.F., 2010. Genomic polymorphisms in sickle cell disease: implications for clinical diversity and treatment. Expert. Rev. Hematol. 3, 443-458.

Fredholm, B.B., Chen, J.F., Cunha, R.A., Svenningsson, P., Vaugeois, J.M., 2005. Adenosine and brain function. Int. Rev. Neurobiol. 63, 191-270.

Hasko, G., Linden, J., Cronstein, B., Pacher, P., 2008. Adenosine receptors: therapeutic aspects for inflammatory and immune diseases. Nat. Rev. Drug Discov. 7, 759-770.

Hebbel, R.P., 1991. Beyond hemoglobin polymerization: the red blood cell membrane and sickle disease pathophysiology. Blood 77, 214-237.

Hirschhorn, R., Yang, D.R., Israni, A., 1994. An Asp8Asn substitution results in the adenosine deaminase (ADA) genetic polymorphism (ADA 2 allozyme): occurrence on different chromosomal backgrounds and apparent intragenic crossover. Ann. Hum. Genet. 58, 1-9.

Hopkinson, D.A., Cook, P.J., Harris, H., 1969. Further data on the adenosine deaminase (ADA) polymprphism and a report of a new phenotype. Ann. Hum. Genet. 32 361-367.

Ingram, V.M., 1957. Gene mutations in human haemoglobin: the chemical difference between normal and sickle cell haemoglobin. Nature 180, 326-328.

Jacobson, K.A., Gao, Z.G., 2006. Adenosine receptors as therapeutic targets. Nat. Rev. Drug Discov. 5, 247-264.

Keen, J.H., Habig, W.H., Jakoby, W.B., 1976. Mechanism for the several activities of the glutathione S-transferases. J. Biol. Chem. 251, 6183-6188.

Lettre, G., 2012. The search for genetic modifiers of disease severity in the beta-hemoglobinopathies. Cold Spring Harb. Perspect. Med. 2.

Madigan, C., Malik, P., 2006. Pathophysiology and therapy for haemoglobinopathies. Part I: sickle cell disease. Expert Rev. Mol. Med. 8, 1-23.

Marengo-Rowe, A.J., 1965. Rapid electrophoresis and quantitation of haemoglobins on cellulose acetate. J. Clin. Pathol. 18, 790-792.

Mazzotti, D.R., Guindalini, C., de Souza, A.A., Sato, J.R., Santos-Silva, R., Bittencourt, L.R. Tufik, S., 2012. Adenosine deaminase polymorphism affects sleep EEG spectral power in a large epidemiological sample. PLoS One 7, e44154.

McDonald, J.H., 2014. Handbook of Biolological Statistics. 3rd ed. Sparky House Publishing, Baltimore, Maryland.

Mi, T., Abbasi, S., Zhang, H., Uray, K., Chunn, J.L., Xia, L.W., Molina, J.G., Weisbrodt, N.W., Kellems, R.E., Blackburn, M.R., Xia, Y., 2008. Excess adenosine in murine penile 
erectile tissues contributes to priapism via A2B adenosine receptor signaling. J. Clin. Invest. 118, 1491-1501.

Nunes, D.P.T., Spegiorin, L.C.J.F., Mattos, C.C.B.d., Oliani, A.H., Vaz-Oliani, D.C.M., Mattos, L.C.d., 2011. The ADA*2 allele of the adenosine deaminase gene (20q13.11) and recurrent spontaneous abortions: an age-dependent association. Clinics 66, 1929-1933.

Persico, A.M., Militerni, R., Bravaccio, C., Schneider, C., Melmed, R., Trillo, S., Montecchi, F., Palermo, M.T., Pascucci, T., Puglisi-Allegra, S., Reichelt, K.L., Conciatori, M., Baldi, A., Keller, F., 2000. Adenosine deaminase alleles and autistic disorder: case-control and family-based association studies. Am. J. Med. Genet. 96, 784-790.

Piel, F.B., Hay, S.I., Gupta, S., Weatherall, D.J., Williams, T.N., 2013. Global burden of sickle cell anaemia in children under five, 2010-2050: modelling based on demographics, excess mortality, and interventions. PLoS Med. 10, 1-14.

Quinn, G.P., Keough, M.J., 2002. Experimental Design and Data Analysis for Biologists. Cambridge University Press, New York.

Rees, D.C., Gibson, J.S., 2012. Biomarkers in sickle cell disease. Br. J. Haematol. 156 433-445.

Rees, D.C., Williams, T.N., Gladwin, M.T., 2010. Sickle-cell disease. Lancet 376, 2018-2031.

Rodriguez-Ariza, A., Toribio, F., Lopez-Barea, J., 1994. Rapid determination of glutathione status in fish liver using high-performance liquid chromatography and electrochemical detection. J. Chromatogr. B Biomed. Appl. 656, 311-318.

Safranow, K., Rzeuski, R., Binczak-Kuleta, A., Czyzycka, E., Skowronek, J., Jakubowska, K. Wojtarowicz, A., Loniewska, B., Ciechanowicz, A., Kornacewicz-Jach, Z., Chlubek, D., 2007. $\mathrm{ADA}^{*} 2$ allele of the adenosine deaminase gene may protect against coronary artery disease. Cardiology 108, 275-281.

Saiki, R.K., Scharf, S., Faloona, F., Mullis, K.B., Horn, G.T., Erlich, H.A., Arnheim, N., 1985. Enzymatic amplification of beta-globin genomic sequences and restriction site analysis for diagnosis of sickle cell anemia. Science 230, 1350-1354.
Sambrook, J., Fritsch, E.F., Maniatis, T., 1989. Molecular Cloning: A Laboratory Manual, Cold Spring Harbor Laboratory Press. Cold Spring Harbor, New York.

Sies, H., Koch, O.R., Martino, E., Boveris, A., 1979. Increased biliary glutathione disulfide release in chronically ethanol-treated rats. FEBS Lett. 103, 287-290.

Silva, D.G., Belini Junior, E., Torres Lde, S., Ricci Junior, O., Lobo Cde, C., Bonini-Domingos, C.R., de Almeida, E.A., 2011. Relationship between oxidative stress, glutathione Stransferase polymorphisms and hydroxyurea treatment in sickle cell anemia. Blood Cells Mol. Dis. 47, 23-28.

Silva, D.G.H., Júnior-Ricci, O., Almeida, E.A., Bonini-Domingos, C.R., 2015. Potential utility of melatonin as an antioxidant therapy in the management of sickle cell anemia. J. Pineal Res. 58, 178-188

Steinberg, M.H., Sebastiani, P., 2012. Genetic modifiers of sickle cell disease. Am. J. Hematol. 87, 795-803.

Stuart, M.J., Nagel, R.L., 2004. Sickle-cell disease. Lancet 364, 1343-1360.

Vella, F., 1968. Acid-agar gel electrophoresis of human hemoglobins. Am. J. Clin. Pathol. 49, 440-442.

Weissmann, J., Vollmer, M., Pribilla, O., 1982. Survey of the distribution of adenosine deaminase and superoxide dismutase markers in different populations. Hum. Hered. 32, 344-356.

Zhang, Y., Xia, Y., 2012. Adenosine signaling in normal and sickle erythrocytes and beyond. Microbes Infect. 14, 863-873.

Zhang Y., Dai, Y., Wen, J., Zhang, W. Grenz, A, Sun, H., Tao, L., Lu, G, Alexander, D.C. Milburn, M.V., Carter-Dawson, L., Lewis, D.E., Zhang, W., Eltzschig, H.K., Kellems, R.E., Blackburn, M.R., Juneja, H.S., Xia, Y., 2011. Detrimental effects of adenosine signaling in sickle cell disease. Nat. Med. 17, 79-86. 